\title{
Chemical risk assessment based on in vitro and human biomonitoring data: A case
} study on thyroid toxicants

Johansson, Hanna Katarina Lilith; Boberg, Julie; Dybdahl, Marianne; Axelstad, Marta; Vinggaard, Anne Marie

\section{Published in:}

Current Opinion in Toxicology

Link to article, DOI:

10.1016/j.cotox.2018.12.001

Publication date:

2019

Document Version

Peer reviewed version

Link back to DTU Orbit

Citation (APA):

Johansson, H. K. L., Boberg, J., Dybdahl, M., Axelstad, M., \& Vinggaard, A. M. (2019). Chemical risk assessment based on in vitro and human biomonitoring data: A case study on thyroid toxicants. Current Opinion in Toxicology, 15, 8-17. https://doi.org/10.1016/j.cotox.2018.12.001

\section{General rights}

Copyright and moral rights for the publications made accessible in the public portal are retained by the authors and/or other copyright owners and it is a condition of accessing publications that users recognise and abide by the legal requirements associated with these rights.

- Users may download and print one copy of any publication from the public portal for the purpose of private study or research.

- You may not further distribute the material or use it for any profit-making activity or commercial gain

- You may freely distribute the URL identifying the publication in the public portal 
1 Chemical risk assessment based on in vitro and human biomonitoring data: $\mathrm{A}$ case study on thyroid toxicants

3 Hanna KL Johansson, Julie Boberg, Marianne Dybdahl, Marta Axelstad, Anne Marie Vinggaard

Affiliations: National Food Institute, Technical University of Denmark, Kemitorvet building 202, 2800 Kgs.

8

Lyngby, Denmark

9 Corresponding author: Anne Marie Vinggaard, annv@food.dtu.dk

Keywords: Risk assessment, in vitro, human biomonitoring, thyroid toxicity, environmental

17 chemicals, PFOS 


\section{Abstract}

21 Today detailed risk assessment can only be performed for a few percent of the total number of current-use chemicals due to lack of data. Toxicity data is therefore needed for a substantial number of untested chemicals, a task that requires improved and faster chemical risk assessment strategies that are cost-efficient,

24 human relevant and ethically responsible. In this commentary we use a case study on five known thyroid toxic chemicals (perfluorooctanesulfonic acid (PFOS), triclosan, tetrabromobisphenol A (TBBPA), decabromodiphenyl ether (BDE-209), and hexabromocyclododecane (HBCD)) to explore the use of in vitro data for hazard assessment together with human biomonitoring (HBM) data for exposure assessment when evaluating human risk. Based on the case study we conclude that in vitro and HBM data can be used for risk ranking of chemicals. We envision that an in vitro/HBM approach can use data from studies such as the big European initiative HBM4EU together with human relevant in vitro data to make alternative risk assessment more valuable to finally be able to 'stand-alone'. 


\section{Changing the paradigm for chemical risk assessment}

Today we only have adequate information to perform detailed risk assessment for a few percent of the total number of current-use chemicals [1]. This reflects a considerable data gap, which is a bottleneck for prediction of human health effects caused by exposure to chemicals. We therefore need to gather or predict more toxicity and exposure data for a substantial number of untested chemicals, a task that - for many reasons - should not be solved by use of traditional animal-based methods only. Hence, improved and faster chemical risk assessment strategies are required to evaluate individual chemicals for which we need knowledge on human safety [2,3]. Here we propose a framework on how to risk rank chemicals based on in vitro data and human biomonitoring data (Fig. 1).

\subsection{The current paradigm and challenges}

Chemical hazard characterization is traditionally based on experimental animal data - often rodent data - for various organ toxicities, reproductive toxicity, carcinogenic effects and mutagenic effects [4]. While such data can be of great value there are several challenges, which complicates chemical risk assessments based solely on this information:

- A scientific challenge exists, as rodent studies do not always predict human responses. Comparison of human and rodent toxicity data for 150 pharmaceuticals showed that rodents predicted $43 \%$ of human responses [5].

- A practical challenge exists, as in vivo data is lacking for the majority of the industrial chemicals in current use [6].

- An ethical challenge exists, as based on the 3R principles [7], reductions on the use of animals for experimental toxicity studies should be made due to ethical reasons. This has resulted in political and 
public pressure as well as EU legislation for test of cosmetics [8] where some in vitro approaches already exist.

Human exposure assessment of a specific chemical is often based on data derived separately for various relevant sources. For instance, exposure via food is often derived from data on chemical concentrations in various food items and average data for human food intake patterns, whereas exposure to the same chemical via cosmetics is assessed separately. Assessing aggregate exposures is thus a challenge $[9,10]$ and still large data gaps exists on human exposure to chemicals [11]. Human internal exposure assessed via human biomonitoring (HBM) is a measure of aggregated exposure but are not routinely used in chemical risk assessment [12]. Yet HBM data is increasingly being gathered all over Europe (HBM4EU [13]) and US (NHANES [14]), presenting a great opportunity to evaluate human exposure across sources.

\subsection{Towards a paradigm shift}

A decade ago, the United States National Research Council presented a vision for chemical toxicity testing in the $21^{\text {st }}$ century, in which computational biology and in vitro tests based on human biology play a central role [3]. Following this, high-throughput screening (HTS) programs such as ToxCast and Tox21 [2,15,16] were initiated. Such HTS systems, together with computational biology and "omics methods", have generated data on hazard for large numbers of chemicals in a cost-efficient, human relevant and ethical way $[2,17]$. Several studies have been published on the use of HTS data in reverse dosimetry models for estimation of human exposure and ranking of chemicals [18-21]. In these studies, external intake dose was used as the measure of exposure, whereas we in the present study explore the use of HBM data as the measure of internal exposure. We argue that in vitro data for hazard assessment together with HBM data for exposure assessment has a future potential to accommodate some of the scientific, practical and ethical challenges we are presently facing. Our long-term vision is that the use of defined panels of in vitro tests combined with human HBM data for the chemical(s) in question can contribute significantly to chemical 
regulation. For the purpose of this publication we present a case study with well-known thyroid toxic chemicals.

\section{Case study on thyroid toxicants}

\subsection{Methodology}

We decided to focus on chemicals that disturb thyroid hormone levels as this is an emerging endocrine mechanism of action for which new in vitro testing strategies are being developed. Our exercise was hypothesized to highlight data gaps that might require future attention. Seventeen compounds were selected for investigation based on their known thyroid toxic effect in vivo and relevant human exposure [12]. Out of these seventeen, five were selected as model compounds based on relevance and available literature on in vitro and HBM data; perfluorooctanesulfonic acid (PFOS), triclosan, tetrabromobisphenol A (TBBPA), decabromodiphenyl ether (BDE-209), and hexabromocyclododecane (HBCD). A literature search was conducted to extract HBM data (NHANES [22] and PubMed) and thyroid relevant in vitro data (PubMed and ToxCast database [23]). For comparison we also included animal in vivo studies from which NOAELs for thyroid effects were derived. To enable comparison across HBM, in vitro and in vivo studies, chemical concentrations in human and animal blood was transformed to $\mathrm{nM}$. The methodology is described in detail in the Supplementary material, but in short: chemical blood levels from epidemiological and in vivo studies were re-calculated from the unit $\mathrm{g}$ chemical/ $\mathrm{g}$ lipid or $\mathrm{g}$ chemical/ $\mathrm{g}$ wet weight of blood to $\mathrm{nM}$. For triclosan the calculation of human internal concentrations differed, as triclosan has a short half-life and is usually measured in urine. Blood levels were therefore estimated by calculation of daily intake based on concentrations found in urine [24] and hereafter a simplified one-compartment toxicokinetic model was applied [25].

Risk characterization ratios (RCRs) were calculated for each chemical by division of the exposure estimate based on HBM data with a reference value (RV) based on in vitro data (RCR=exposure/RV) [26]. The RCR value reflects whether exposures exceed the concentrations considered "safe". Thus, RCR values $>1$ indicate that human exposure levels may be associated with a potential risk. RVs were based on in vitro data from one experimental study for each chemical that was selected based on expert judgement in terms of relevance 
of the mechanism of action and reliability of the study. . From the five selected in vitro studies, the "no observed effect concentration' (NOEC) value was used for RCR calculation. For chemicals with no reported NOEC an extrapolation factor of 10 from LOEC to NOEC was used. Furthermore, we included studies in zebrafish larvae for PFOS, TBBPA, and BDE-209, even though the larvae is not considered an in vitro model, only the embryo is [27]. Studies considered to be potential outliers or not showing a mechanism known to be thyroid specific, were excluded.

The in vitro studies included are presented in Table 1 . The data shows a wide field of tested in vitro end points with indications of effects on well-known thyroid endpoints such as antagonism of the thyroid receptor (TR) [28] and transthyretin (TTR) binding [29] by PFOS, activation of the constitutive androstane receptor (CAR) by a triclosan metabolite [30], TTR binding by TBBPA [31], TH reduction of BDE-209 in zebrafish [32-34], as well as some thyroid-specific effect in hepatocytes by HBCD [35].

To take uncertainty of HBM data into account the exposure values were calculated based on an average of means (PFOS, triclosan, TBBPA) or medians (BDE-209, HBCD). Exposure data with values below limit of quantification/limit of detection, measurements in other matrices than blood or urine, studies from Asian countries and occupational exposure studies, were excluded.

\subsection{Data availability}

Data on exposure and toxicity collected from HBM, in vitro and in vivo studies for the five chemicals are depicted in Fig. 2 and the references used are shown in Table 1.

Due to limited resources, the HBM data included for PFOS and triclosan were limited to one representative European study and data from the NHANES [22]. For TBBPA, BDE-209, and HBCD a thorough review of the literature was conducted. For TBBPA, three HBM studies were included and several excluded due to several studies with TBBPA levels below limit of quantification/limit of detection. For BDE-209, some studies were also excluded due to measurements below the limit of detection/limit of quantification. Exclusion of these data may somewhat skew the results, leading to an overestimation of the exposure for these compounds. 
The included in vitro studies have tested thyroid toxicity for a wide range of endpoints (Table 1), but not all

140 chemicals have been tested for all relevant mechanisms of thyroid toxicity. This approach, which includes a range of assays, is analogous to classical risk assessment where several endpoints are evaluated and only the most sensitive endpoint is used in the end.

\subsection{Output and ranking}

Ranking of the five compounds in terms of calculated RCR values based on in vitro NOEC values showed that PFOS was associated with the highest risk $(\mathrm{RCR}=8)$ and HBCD with the lowest $(\mathrm{RCR}=0.0001)$ (Table 2):

PFOS > > TBBPA > BDE-209 > Triclosan > HBCD

150

Based on this analysis, exposure to PFOS alone is highlighted as a potential human health risk. The association is of even greater concern considering that humans are exposed to several perfluorinated compounds [36] that may have the same or similar mode(s) of action, which can cause cumulative effects. The RCR ranking shows that PFOS needs further attention, although its use is restricted within the US [37] and EU [38].

It should be noted, however, that the RCR values are subject to great uncertainties, both for the hazard and exposure data. The RCR values presented here should therefore be regarded as indicative values suggested as examples in this proposed framework, and not as values that should readily be used for risk assessment purposes.

As can be seen in Fig. 2 the in vitro active concentrations and the blood levels at LOAELs and/or NOAELs from animal experiments were not that different. However, for PFOS effects are seen at lower concentrations in vitro than in vivo, whereas for triclosan the situation is opposite. This reflects that toxicity of some perfluorinated chemicals generally seem to be underestimated by animal studies [39] and that human data and physiologically-based kinetic modelling are needed for a proper risk assessment of this group of chemicals. For triclosan the difference may be explained by species differences in CYP induction [40]. In 
humans and rodents, increased liver catabolism of thyroid hormones has been identified as one of the primary modes of action of triclosan $[40,41]$. However, data from nuclear receptor reporter assays show that CAR and PXR activation by triclosan differs between the human and rodent [40], which indicates important species differences in thyroid hormone catabolism.

\section{Future application of in vitro and biomonitoring data for risk assessment}

\subsection{A panel of human-based in vitro assays}

We found limited relevant in vitro data and data that covers thyroid toxic mode(s) of action and/or key initiating events for the selected chemicals. Furthermore, there is a need for more human-based in vitro models as we in this case study only found a few assays based on human biology.

We suggest that defined panels of human-based in vitro assays are used to ensure that several important modes of action are covered, which is in line with the vision from the US National Research Council [3]. A defined panel of human-based in vitro assays would enable comparison and ranking of chemicals with different potencies, either by use of RCR values or a similar ratio. In terms of the practical challenge with thousands of untested chemicals on the market, in vitro assays enable high throughput test strategies such as the ToxCast and Tox21 initiatives in the US $[2,15,16]$.

Toxicity is in some cases caused by metabolites and not the parent compound. The metabolic capacity of the in vitro system is therefore important to consider [42] and there are both extra- and intracellular options that can allow evaluation of metabolic capacity in the in vitro panel [43-45]. Furthermore, in order to obtain a quantitative link between HBM data and in vitro outputs - thereby improving predictions - it would be relevant to correct the in vitro output for factors such as protein binding, evaporation, binding to test plates/tubes/pipettes etc. in order to obtain the true intracellular concentration $[46,47]$.

\subsection{HBM data for exposure assessment}


Use of HBM data for exposure assessment is a promising approach as it measures the sum of chemical contributions from one or more routes of exposure as well as from different sources [48]. HBM data is also valuable for assessment of chemicals with unknown or poorly characterized exposure pathways [49] and thus the integrated internal exposure levels can be used as a better and more relevant measure [50]. Furthermore, external exposure modelling, based on e.g. food consumption patterns and cosmetics use, is likely a greater source of uncertainty than biological measurements [50,51]. On the other hand, HBM data cannot be obtained for all compounds due to e.g. shared metabolites, and an important drawback is that it can only be used for chemicals already on the market [48]. Evaluation of exposure based on HBM data will therefore always be a retrospective rather than preventive approach. Furthermore, HBM data does not contribute with information concerning timing and source of the exposure [48,52], which is central to chemical regulation.

\subsection{Other examples of in vitro or HBM based risk assessment}

There are other examples of in vitro based risk assessment in the literature, however, many of these differ from the present approach by use of external exposure dose (oral intake, $\mathrm{mg} / \mathrm{kg}$ ) [18-21,53], whereas we have used internal exposure dose (blood concentration, $\mathrm{nM}$ ) based on measured HBM data. Two examples are Campell et al. [53] and Ring et al. [18]:

Campbell et al. [53], used in vitro based $\mathrm{EC}_{10}$ values for estrogenic activity of parabens as surrogate "safe exposure doses". They used a Margin of Safety approach for risk assessment, which in essence is similar to our approach, except that the inverse ratio was calculated, i.e. division of a no-effect level with an exposure estimate.

Ring et al. [18] used data from ToxCast high-throughput in vitro screening assays applied for prioritization. Bioactive in vitro concentrations were extrapolated to oral equivalent doses by reverse dosimetry, and these doses were compared to external exposure doses calculated from HBM data. If the estimated exposure is higher than the dose needed to obtain a bioactive concentration in blood, a potential risk is identified. Interestingly, in that study triclosan was identified as one of the compounds with the smallest difference between exposure and activity, i.e. as the most problematic and a priority for further evaluation [18]. 
HBM data have been applied in studies where their potential as exposure estimates has been investigated. A comprehensive case study on benzene has been conducted [54], however, approaches more similar to the one used in the present case study has been conducted by Hays et al. [51] and Aylward \& Hays [50]. In both these studies the authors concluded that internal dose measures from HBM studies are less uncertain than estimated external doses in risk assessment.

\section{Conclusion}

We used a case study on five thyroid toxic compounds with differential mechanistic profiles to investigate the potential use of human biomonitoring $(\mathrm{HBM})$ together with in vitro data for informing human risk assessment. We conclude that calculation of risk characterization ratios based on HBM and in vitro data is a helpful tool for ranking chemicals and for designing follow-up studies.

The case study highlighted the pros and cons of informing the risk assessment process with in vitro and HBM data and demonstrated that such data can be used for risk ranking of chemicals. Moreover, this approach may be used for pinpointing chemicals for which species differences may play a major role, thereby stressing the importance of basing the risk assessment on human-relevant data. Our vision is that an in vitro/HBM approach can use the HBM4EU project - in parallel to the NHANES project in the US together with more comprehensive human relevant in vitro data to make 'alternative' risk assessment much more valuable to finally be able to 'stand-alone'.

\section{Acknowledgements}

238 We would like to thank Dr Terje Svingen for editorial input to the text. This work was financially supported 239 by the Ministry of Environment and Food of Denmark. 


\section{Conflict of interest}

241 Declarations of interest: None.

242

243

244

245

246

247

248

249

250

251

252

253

254

255

256

257 
Table 1: Case study literature overview for the five selected chemicals PFOS, triclosan, TBBPA, BDE-209 and HBCD. The first row shows the human biomonitoring (HBM) data with country of origin and references. The second row shows the in vitro data with endpoints measured, $\mathrm{LOEC}_{\mathrm{EC}} \mathrm{x}$ values, the study used for calculation of risk characterization ratio (RCR) marked in bold, as well as references. The third row shows the in vivo data from animal experiments with endpoints and references.

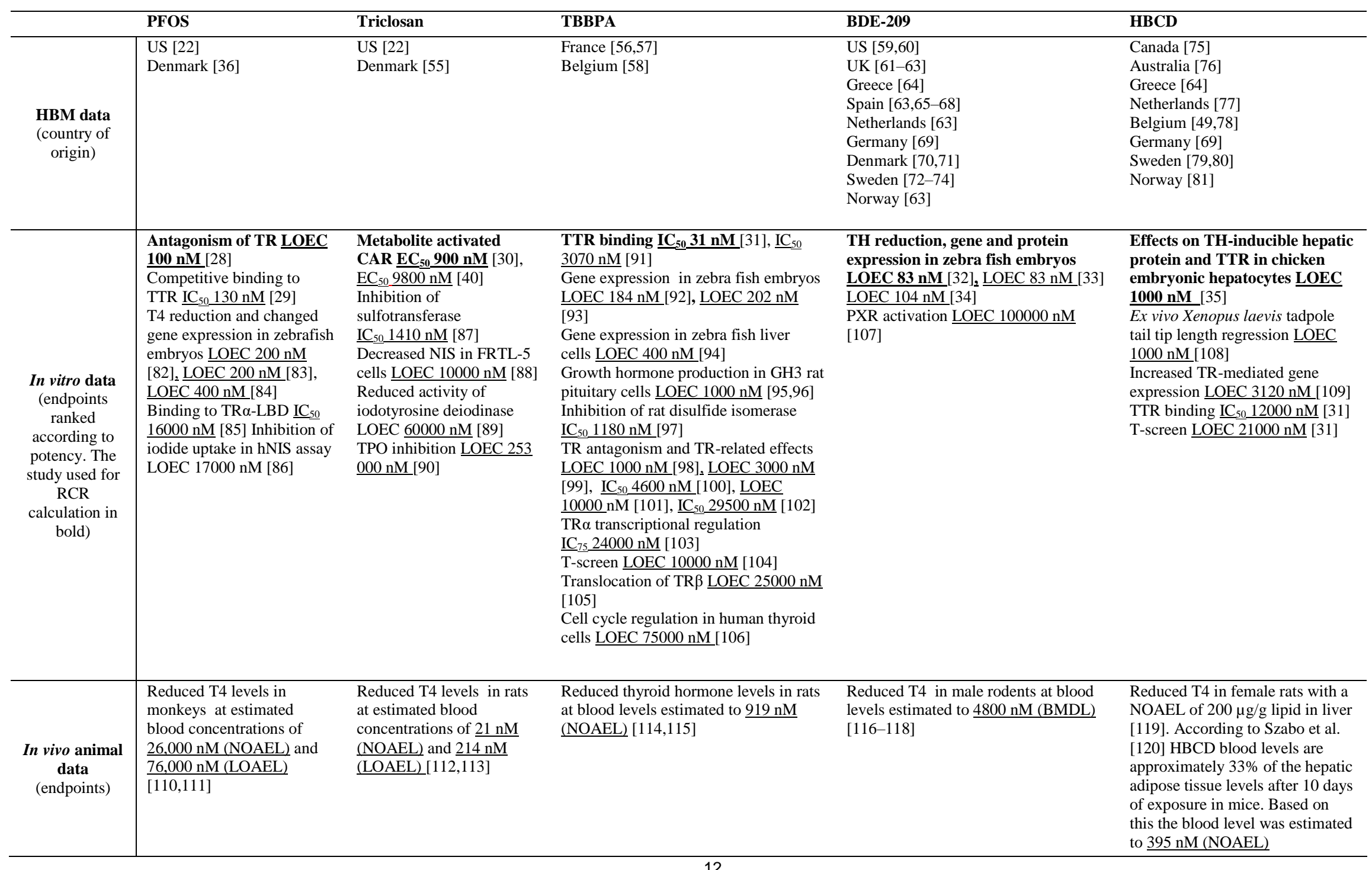


261 Table 2: Human biomonitoring (HBM) data, in vitro data and calculated risk characterization ratios (RCRs) for the five chemicals $(\mathrm{RCR}=$ exposure (HBM data) /reference value (in vitro))

263

\begin{tabular}{|c|c|c|c|c|c|}
\hline Data type & PFOS & Triclosan & TBBPA & BDE-209 & $\mathrm{HBCD}$ \\
\hline $\begin{array}{l}\text { Human biomonitoring data } \\
\text { Mean }(n M)\end{array}$ & 25 & 0.04 & 0.2 & 0.05 & 0.01 \\
\hline $\begin{array}{l}\text { In vitro data } \\
\operatorname{NOEC}(n M)\end{array}$ & 3 & 90 & 3.1 & 8.3 & 100 \\
\hline Risk Characterization Ratio & 8 & 0.0004 & 0.06 & 0.006 & 0.0001 \\
\hline
\end{tabular}




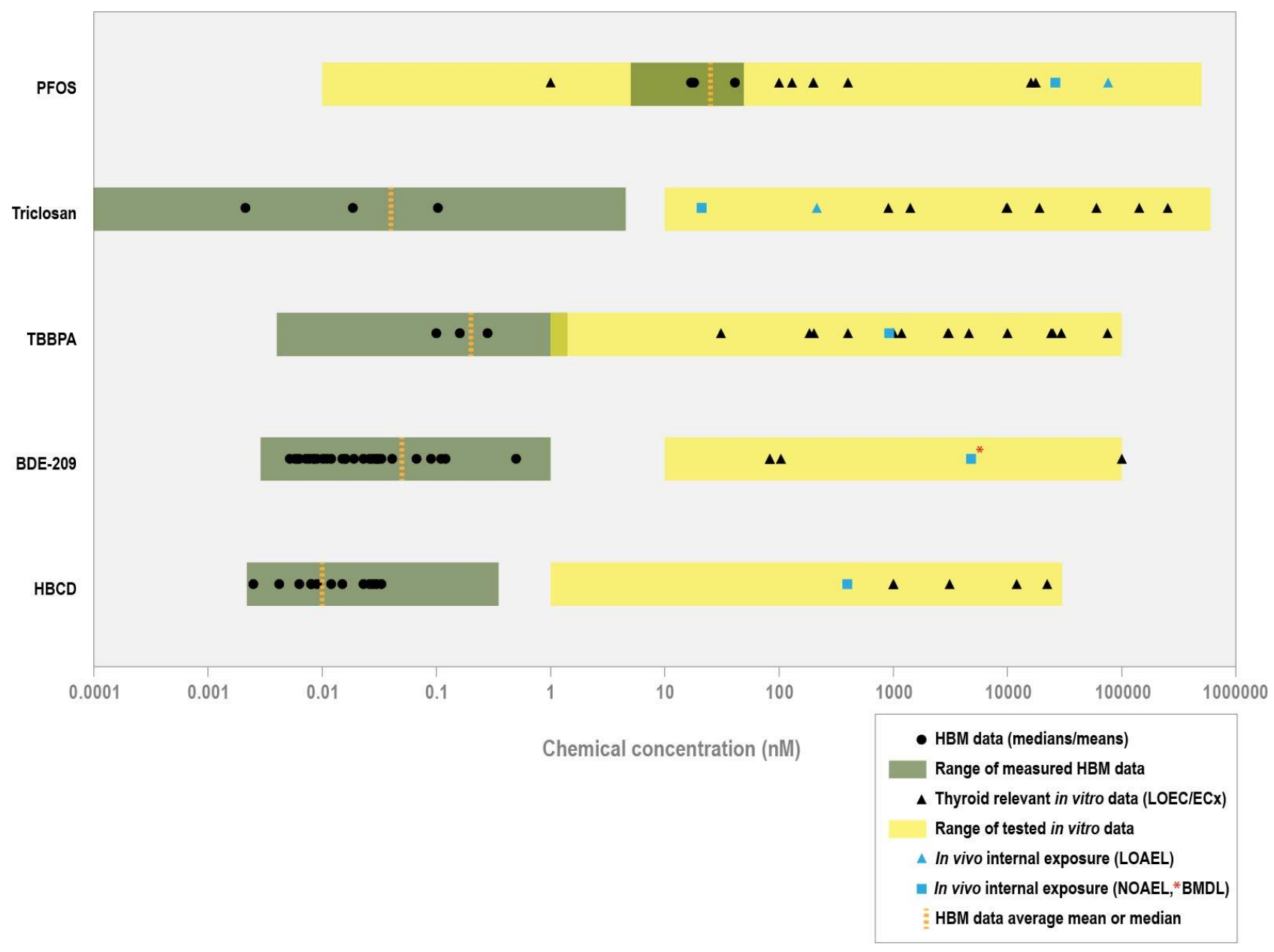

Figure 1. HBM data (green bars and dots), in vitro data (yellow bars and triangles), and in vivo data from animal experiments (blue triangles and squares) are depicted in this figure. The measured chemical levels in humans are generally lower than the effect concentrations found in vitro and in vivo. The exception is PFOS where the measured human levels and the effective concentrations in vitro are relatively close. Furthermore, average HBM values (orange, stippled lines) are relatively similar for all five chemicals except PFOS, where the internal human concentrations are higher. adverse effect level, $N O A E L=$ no observed adverse effect level; $B M D L=$ bench mark dose level) 


\section{References}

286 [1] United States Government Accountability Office, TOXIC SUBSTANCES: EPA Has Increased

[2] F.S. Collins, G.M. Gray, J.R. Bucher, Transforming Environmental Health Protection, Science (80-. ). 319 (2008) 906-907. doi:10.1126/science.1154619.

[3] National Research Council, Toxicity Testing in the 21st Century, National Academies Press, Washington, D.C., 2007. doi:10.17226/11970.

[5] H. Olson, G. Betton, D. Robinson, K. Thomas, A. Monro, G. Kolaja, P. Lilly, J. Sanders, G. Sipes,

[4] ECHA, Guidance on Information Requirements and Chemical Safety Assessment, (2011). https://echa.europa.eu/guidance-documents/guidance-on-information-requirements-and-chemicalsafety-assessment (accessed July 3, 2018). W. Bracken, M. Dorato, K. Van Deun, P. Smith, B. Berger, A. Heller, Concordance of the Toxicity of Pharmaceuticals in Humans and in Animals, Regul. Toxicol. Pharmacol. 32 (2000) 56-67. doi:10.1006/rtph.2000.1399.

[6] A. Springer, H. Herrmann, D. Sittner, U. Herbst, A. Schulte, REACH Compliance: Data Availability of REACH Registrations, Part 1: Screening of Chemicals > 1000 tpa, Berlin, 2015. https://www.umweltbundesamt.de/publikationen/reach-compliance-data-availability-of-reach.

[7] B. Rusche, The 3Rs and animal welfare - conflict or the way forward?, ALTEX Altern. Zu Tierexperimenten. 20 (2003) 63-76.

[8] European Parliament and the Council, Regulation (EC) No 1223/2009 on cosmetic products, (n.d.). https://eur-lex.europa.eu/legal-content/EN/ALL/?uri=CELEX:02009R1223-20160812.

[9] D. Comiskey, A.M. Api, C. Barrett, G. Ellis, C. McNamara, C. O’Mahony, S.H. Robison, J. Rose, B. Safford, B. Smith, S. Tozer, Integrating habits and practices data for soaps, cosmetics and air care products into an existing aggregate exposure model, Regul. Toxicol. Pharmacol. 88 (2017) 144-156. doi:10.1016/j.yrtph.2017.05.017. 
[10] T.J. Lentz, G.S. Dotson, P.R.D. Williams, A. Maier, B. Gadagbui, S.P. Pandalai, A. Lamba, F. Hearl, M. Mumtaz, Aggregate Exposure and Cumulative Risk Assessment-Integrating Occupational and Non-occupational Risk Factors, J. Occup. Environ. Hyg. 12 (2015) S112-S126. doi:10.1080/15459624.2015.1060326.

[11] P.P. Egeghy, R. Judson, S. Gangwal, S. Mosher, D. Smith, J. Vail, E.A. Cohen Hubal, The exposure data landscape for manufactured chemicals, Sci. Total Environ. 414 (2012) 159-166. doi:10.1016/j.scitotenv.2011.10.046.

[12] P.B. Larsen, J. Boberg, P.B. Poulsen, T.A. Mørck, H.B. Boyd, D.N. Andersen, M. Axelsted, U. Hass, Exposure of children and unborn children to selected chemical substances, 2017. https://www2.mst.dk/Udgiv/publications/2017/04/978-87-93529-84-7.pdf.

[13] HBM4EU, HBM4EU Sci. Policy a Heal. Futur. (n.d.). https://www.hbm4eu.eu/ (accessed July 11, 2018).

[14] NHANES, NHANES. (n.d.). https://www.cdc.gov/nchs/nhanes/index.htm (accessed July 11, 2018).

[15] R.J. Kavlock, C.P. Austin, R.R. Tice, Toxicity Testing in the 21st Century: Implications for Human Health Risk Assessment, Risk Anal. 29 (2009) 485-487. doi:10.1111/j.1539-6924.2008.01168.x.

[16] R. Kavlock, K. Chandler, K. Houck, S. Hunter, R. Judson, N. Kleinstreuer, T. Knudsen, M. Martin, S. Padilla, D. Reif, A. Richard, D. Rotroff, N. Sipes, D. Dix, Update on EPA's ToxCast Program: Providing High Throughput Decision Support Tools for Chemical Risk Management, Chem. Res. Toxicol. 25 (2012) 1287-1302. doi:10.1021/tx3000939.

[17] M.R. Gwinn, D.A. Axelrad, T. Bahadori, D. Bussard, W.E. Cascio, K. Deener, D. Dix, R.S. Thomas, R.J. Kavlock, T.A. Burke, Chemical Risk Assessment: Traditional vs Public Health Perspectives, Am. J. Public Health. 107 (2017) 1032-1039. doi:10.2105/AJPH.2017.303771.

[18] C.L. Ring, R.G. Pearce, R.W. Setzer, B.A. Wetmore, J.F. Wambaugh, Identifying populations sensitive to environmental chemicals by simulating toxicokinetic variability, Environ. Int. 106 (2017) 105-118. doi:10.1016/j.envint.2017.06.004.

[19] N.S. Sipes, J.F. Wambaugh, R. Pearce, S.S. Auerbach, B.A. Wetmore, J.-H. Hsieh, A.J. Shapiro, D. Svoboda, M.J. DeVito, S.S. Ferguson, An Intuitive Approach for Predicting Potential Human Health 
Risk with the Tox21 10k Library, Environ. Sci. Technol. 51 (2017) 10786-10796. doi:10.1021/acs.est.7b00650.

[20] B.A. Wetmore, J.F. Wambaugh, B. Allen, S.S. Ferguson, M.A. Sochaski, R.W. Setzer, K.A. Houck, C.L. Strope, K. Cantwell, R.S. Judson, E. LeCluyse, H.J. Clewell, R.S. Thomas, M.E. Andersen, Incorporating High-Throughput Exposure Predictions With Dosimetry-Adjusted In Vitro Bioactivity to Inform Chemical Toxicity Testing, Toxicol. Sci. 148 (2015) 121-136. doi:10.1093/toxsci/kfv171.

[21] B.A. Wetmore, J.F. Wambaugh, S.S. Ferguson, M.A. Sochaski, D.M. Rotroff, K. Freeman, H.J. Clewell, D.J. Dix, M.E. Andersen, K.A. Houck, B. Allen, R.S. Judson, R. Singh, R.J. Kavlock, A.M. Richard, R.S. Thomas, Integration of Dosimetry, Exposure, and High-Throughput Screening Data in Chemical Toxicity Assessment, Toxicol. Sci. 125 (2012) 157-174. doi:10.1093/toxsci/kfr254.

[22] NHANES, Fourth National Report on Human Exposure to Environmental Chemicals, Department of Health and Human Services Centers for Disease Control and Prevention, 2009. http://www.cdc.gov/exposurereport/pdf/fourthreport.pdf.

[23] U. EPA, ToxCast, (n.d.). https://actor.epa.gov/dashboard/.

[24] H.M. Koch, K. Becker, M. Wittassek, M. Seiwert, J. Angerer, M. Kolossa-Gehring, Di-nbutylphthalate and butylbenzylphthalate - urinary metabolite levels and estimated daily intakes: pilot study for the German Environmental Survey on children, J. Expo. Sci. Environ. Epidemiol. 17 (2007) 378-387. doi:10.1038/sj.jes.7500526.

[25] H. Fromme, M. Schlummer, A. Möller, L. Gruber, G. Wolz, J. Ungewiss, S. Böhmer, W. Dekant, R. Mayer, B. Liebl, D. Twardella, Exposure of an Adult Population to Perfluorinated Substances Using Duplicate Diet Portions and Biomonitoring Data, Environ. Sci. Technol. 41 (2007) 7928-7933. doi:10.1021/es071244n.

[26] ECHA, Guidance on Information Requirements and Chemical Safety Assessment - Part E: Risk Characterisation, 2016. http://echa.europa.eu/documents/10162/13632/information_requirements_r11_en.pdf.

[27] OECD, OECD guidelines for the testing of chemicals. Fish embryo acute toxicity (FET) test. TG 236, 2013. doi:10.1787/9789264067332-en. 
[28] G. Du, J. Hu, H. Huang, Y. Qin, X. Han, D. Wu, L. Song, Y. Xia, X. Wang, Perfluorooctane sulfonate (PFOS) affects hormone receptor activity, steroidogenesis, and expression of endocrinerelated genes in vitro and in vivo, Environ. Toxicol. Chem. 32 (2013) 353-360. doi:10.1002/etc.2034.

[29] X.-M. Ren, W.-P. Qin, L.-Y. Cao, J. Zhang, Y. Yang, B. Wan, L.-H. Guo, Binding interactions of perfluoroalkyl substances with thyroid hormone transport proteins and potential toxicological implications, Toxicology. 366-367 (2016) 32-42. doi:10.1016/j.tox.2016.08.011.

[30] P. Ashrap, G. Zheng, Y. Wan, T. Li, W. Hu, W. Li, H. Zhang, Z. Zhang, J. Hu, Discovery of a widespread metabolic pathway within and among phenolic xenobiotics, Proc. Natl. Acad. Sci. 114 (2017) 6062-6067. doi:10.1073/pnas.1700558114.

[31] T. Hamers, J.H. Kamstra, E. Sonneveld, A.J. Murk, M.H.A. Kester, P.L. Andersson, J. Legler, A. Brouwer, In Vitro Profiling of the Endocrine-Disrupting Potency of Brominated Flame Retardants, Toxicol. Sci. 92 (2006) 157-173. doi:10.1093/toxsci/kfj187.

[32] Q. Chen, L. Yu, L. Yang, B. Zhou, Bioconcentration and metabolism of decabromodiphenyl ether (BDE-209) result in thyroid endocrine disruption in zebrafish larvae, Aquat. Toxicol. 110-111 (2012) 141-148. doi:10.1016/j.aquatox.2012.01.008.

[33] Q. Wang, Q. Chen, P. Zhou, W. Li, J. Wang, C. Huang, X. Wang, K. Lin, B. Zhou, Bioconcentration and metabolism of BDE-209 in the presence of titanium dioxide nanoparticles and impact on the thyroid endocrine system and neuronal development in zebrafish larvae, Nanotoxicology. 8 (2014) 196-207. doi:10.3109/17435390.2013.875232.

[34] B. Zhu, Q. Wang, X. Wang, B. Zhou, Impact of co-exposure with lead and decabromodiphenyl ether (BDE-209) on thyroid function in zebrafish larvae, Aquat. Toxicol. 157 (2014) 186-195. doi:10.1016/j.aquatox.2014.10.011.

[35] D. Crump, S. Chiu, C. Egloff, S.W. Kennedy, Effects of Hexabromocyclododecane and Polybrominated Diphenyl Ethers on mRNA Expression in Chicken (Gallus domesticus) Hepatocytes, Toxicol. Sci. 106 (2008) 479-487. doi:10.1093/toxsci/kfn196.

[36] T.A. Mørck, F. Nielsen, J.K.S. Nielsen, V.D. Siersma, P. Grandjean, L.E. Knudsen, PFAS concentrations in plasma samples from Danish school children and their mothers, Chemosphere. 129 
(2015) 203-209. doi:10.1016/j.chemosphere.2014.07.018.

[37] US EPA, PFAS Laws and Regulations, United States Environ. Prot. Agency. (2018). https://www.epa.gov/pfas/pfas-laws-and-regulations (accessed August 16, 2018).

[38] ChemSafetyPRO, Perfluorooctace sulfonic acid and its derivatives (PFOS), PFOS Restriciton limits in EU, ChemSafetyPRO. (2018). http://www.chemsafetypro.com/Topics/Restriction/PFOS_EU_restriction_limit_PFOS_and_REACH _annex_XVII.html (accessed August 16, 2018).

[39] ECHA, ANNEX XV Restriction report proposal for a restriction. Perfluorooctanoic acid (PFOA), PFOA salts and PFOA-related substances, Version 1. (2014) 1-155. https://echa.europa.eu/documents/10162/e9cddee6-3164-473d-b590-8fcf9caa50e7.

[40] K.B. Paul, J.T. Thompson, S.O. Simmons, J.P. Vanden Heuvel, K.M. Crofton, Evidence for triclosaninduced activation of human and rodent xenobiotic nuclear receptors, Toxicol. Vitr. 27 (2013) 20492060. doi:10.1016/j.tiv.2013.07.008.

[41] N. Hanioka, H. Jinno, T. Nishimura, M. Ando, Effect of 2,4,4'-trichloro-2'-hydroxydiphenyl ether on cytochrome P450 enzymes in the rat liver, Chemosphere. 34 (1997) 719-30. http://www.ncbi.nlm.nih.gov/pubmed/9569940.

[42] B.J. Blaauboer, The necessity of biokinetic information in the interpretation of in vitro toxicity data, ATLA Altern. to Lab. Anim. 30 (2002) 85-91.

[43] D.E. DeGroot, A. Swank, R.S. Thomas, M. Strynar, M.-Y. Lee, P.L. Carmichael, S.O. Simmons, mRNA transfection retrofits cell-based assays with xenobiotic metabolism, J. Pharmacol. Toxicol. Methods. 92 (2018) 77-94. doi:10.1016/j.vascn.2018.03.002.

[44] M.T. Donato, A. Lahoz, J.V. Castell, M.J. Gomez-Lechon, Cell Lines: A Tool for In Vitro Drug Metabolism Studies, Curr. Drug Metab. 9 (2008) 1-11. doi:10.2174/138920008783331086.

[45] J. Mollergues, B. van Vugt-Lussenburg, C. Kirchnawy, R.A. Bandi, R.B. van der Lee, M. MarinKuan, B. Schilter, K.C. Fussell, Incorporation of a metabolizing system in biodetection assays for endocrine active substances, ALTEX. 34 (2017) 389-398. doi:10.14573/altex.1611021.

[46] D. Gilbert, P. Mayer, M. Pedersen, A.M. Vinggaard, Endocrine activity of persistent organic 
pollutants accumulated in human silicone implants — Dosing in vitro assays by partitioning from silicone, Environ. Int. 84 (2015) 107-114. doi:10.1016/j.envint.2015.07.008.

[47] Z. Dong, Y. Liu, L. Duan, D. Bekele, R. Naidu, Uncertainties in human health risk assessment of environmental contaminants: A review and perspective, Environ. Int. 85 (2015) 120-132. doi:10.1016/j.envint.2015.09.008.

[48] P.J. Lioy, Exposure science: A view of the past and milestones for the future, Environ. Health Perspect. 118 (2010) 1081-1090. doi:10.1289/ehp.0901634.

[49] L. Roosens, M. Abdallah, S. Harrad, H. Neels, A. Covaci, Exposure to Hexabromocyclododecanes (HBCDs) via Dust Ingestion, but not Diet, Correlates with Concentrations in Human Serum Preliminary Results, Environ. Health Perspect. 117 (2009) 1707-1712. doi:10.1289/ehp.0900869.

[50] L.L. Aylward, S.M. Hays, Biomonitoring-based risk assessment for hexabromocyclododecane (HBCD), Int. J. Hyg. Environ. Health. 214 (2011) 179-187. doi:10.1016/j.ijheh.2011.02.002.

[51] S.M. Hays, L.L. Aylward, J. Driver, J. Ross, C. Kirman, 2,4-D Exposure and risk assessment: Comparison of external dose and biomonitoring based approaches, Regul. Toxicol. Pharmacol. 64 (2012) 481-489. doi:10.1016/j.yrtph.2012.09.001.

[52] A.M. Calafat, Contemporary Issues in Exposure Assessment Using Biomonitoring, Curr. Epidemiol. Reports. 3 (2016) 145-153. doi:10.1007/s40471-016-0075-7.

[53] J.L. Campbell, M. Yoon, H.J. Clewell, A case study on quantitative in vitro to in vivo extrapolation for environmental esters: Methyl-, propyl- and butylparaben, Toxicology. 332 (2015) 67-76. doi:10.1016/j.tox.2015.03.010.

[54] S.M. Arnold, J. Angerer, P.J. Boogaard, M.F. Hughes, R.B. O’Lone, S.H. Robison, A. Robert Schnatter, The use of biomonitoring data in exposure and human health risk assessment: benzene case study, Crit. Rev. Toxicol. 43 (2013) 119-153. doi:10.3109/10408444.2012.756455.

[55] H. Frederiksen, T.K. Jensen, N. Jorgensen, H.B. Kyhl, S. Husby, N.E. Skakkebaek, K.M. Main, A. Juul, A.-M. Andersson, Human urinary excretion of non-persistent environmental chemicals: an overview of Danish data collected between 2006 and 2012, Reproduction. 147 (2014) 555-565. doi:10.1530/REP-13-0522. 
[56] J.-P. Antignac, R. Cariou, D. Maume, P. Marchand, F. Monteau, D. Zalko, A. Berrebi, J.-P. Cravedi, F. Andre, B. Le Bizec, Exposure assessment of fetus and newborn to brominated flame retardants in France: preliminary data, Mol. Nutr. Food Res. 52 (2008) 258-265. doi:10.1002/mnfr.200700077.

[57] R. Cariou, J.-P. Antignac, D. Zalko, A. Berrebi, J.-P. Cravedi, D. Maume, P. Marchand, F. Monteau, A. Riu, F. Andre, B. Le Bizec, Exposure assessment of French women and their newborns to tetrabromobisphenol-A: Occurrence measurements in maternal adipose tissue, serum, breast milk and cord serum, Chemosphere. 73 (2008) 1036-1041. doi:10.1016/j.chemosphere.2008.07.084.

[58] A.C. Dirtu, L. Roosens, T. Geens, A. Gheorghe, H. Neels, A. Covaci, Simultaneous determination of bisphenol A, triclosan, and tetrabromobisphenol A in human serum using solid-phase extraction and gas chromatography-electron capture negative-ionization mass spectrometry, Anal. Bioanal. Chem. 391 (2008) 1175-1181. doi:10.1007/s00216-007-1807-9.

[59] S. Lunder, L. Hovander, I. Athanassiadis, Å. Bergman, Significantly Higher Polybrominated Diphenyl Ether Levels in Young U.S. Children than in Their Mothers, Environ. Sci. Technol. 44 (2010) 5256-5262. doi:10.1021/es1009357.

[60] A. Sjödin, D.G. Patterson, Å. Bergman, Brominated Flame Retardants in Serum from U.S. Blood Donors, Environ. Sci. Technol. 35 (2001) 3830-3833. doi:10.1021/es010815n.

[61] L. Bramwell, A. Fernandes, M. Rose, S. Harrad, T. Pless-Mulloli, PBDEs and PBBs in human serum and breast milk from cohabiting UK couples, Chemosphere. 116 (2014) 67-74. doi:10.1016/j.chemosphere.2014.03.060.

[62] G.O. Thomas, M. Wilkinson, S. Hodson, K.C. Jones, Organohalogen chemicals in human blood from the United Kingdom, Environ. Pollut. 141 (2006) 30-41. doi:10.1016/j.envpol.2005.08.027.

[63] M. van den Berg, R. Houba, H.A. Leslie, R.F. Canton, C. Thomsen, G. Becher, M. Alvarez-Pedrerol, J.S. Deu, M. Steiner, M. van Tongeren, B. Brunekreef, J. de Boer, Serum levels of decabromodiphenyl ether (BDE-209) in women from different European countries and possible relationships with lifestyle and diet, Environ. Int. 107 (2017) 16-24. doi:10.1016/j.envint.2017.06.014.

[64] O.I. Kalantzi, T. Geens, A. Covaci, P.A. Siskos, Distribution of polybrominated diphenyl ethers 
(PBDEs) and other persistent organic pollutants in human serum from Greece, Environ. Int. 37 (2011) 349-353. doi:10.1016/j.envint.2010.10.005.

[65] B. Gómara, L. Herrero, J.J. Ramos, J.R. Mateo, M.A. Fernández, J.F. García, M.J. González, Distribution of Polybrominated Diphenyl Ethers in Human Umbilical Cord Serum, Paternal Serum, Maternal Serum, Placentas, and Breast Milk from Madrid Population, Spain, Environ. Sci. Technol. 41 (2007) 6961-6968. doi:10.1021/es0714484.

[66] M. Garí, J.O. Grimalt, Inverse age-dependent accumulation of decabromodiphenyl ether and other PBDEs in serum from a general adult population, Environ. Int. 54 (2013) 119-127. doi:10.1016/j.envint.2013.01.012.

[67] E. Vizcaino, J.O. Grimalt, A. Fernández-Somoano, A. Tardon, Transport of persistent organic pollutants across the human placenta, Environ. Int. 65 (2014) 107-115. doi:10.1016/j.envint.2014.01.004.

[68] E. Vizcaino, J.O. Grimalt, M.-J. Lopez-Espinosa, S. Llop, M. Rebagliato, F. Ballester, Polybromodiphenyl ethers in mothers and their newborns from a non-occupationally exposed population (Valencia, Spain), Environ. Int. 37 (2011) 152-157. doi:10.1016/j.envint.2010.08.011.

[69] H. Fromme, B. Hilger, M. Albrecht, W. Gries, G. Leng, W. Völkel, Occurrence of chlorinated and brominated dioxins/furans, PCBs, and brominated flame retardants in blood of German adults., Int. J. Hyg. Environ. Health. 219 (2016) 380-388. doi:10.1016/j.ijheh.2016.03.003.

[70] K. Vorkamp, F. Nielsen, H.B. Kyhl, S. Husby, L.B. Nielsen, T. Barington, A.-M. Andersson, T.K. Jensen, Polybrominated Diphenyl Ethers and Perfluoroalkyl Substances in Serum of Pregnant Women: Levels, Correlations, and Potential Health Implications, Arch. Environ. Contam. Toxicol. 67 (2014) 9-20. doi:10.1007/s00244-013-9988-z.

[71] M. Frederiksen, C. Thomsen, M. Frøshaug, K. Vorkamp, M. Thomsen, G. Becher, L.E. Knudsen, Polybrominated diphenyl ethers in paired samples of maternal and umbilical cord blood plasma and associations with house dust in a Danish cohort, Int. J. Hyg. Environ. Health. 213 (2010) 233-242. doi:10.1016/j.ijheh.2010.04.008.

[72] L.M.O. Sahlström, U. Sellström, C.A. de Wit, S. Lignell, P.O. Darnerud, Brominated Flame 
Retardants in Matched Serum Samples from Swedish First-Time Mothers and Their Toddlers, Environ. Sci. Technol. 48 (2014) 7584-7592. doi:10.1021/es501139d.

[73] H. Bjermo, M. Aune, T. Cantillana, A. Glynn, P.M. Lind, P. Ridefelt, P.O. Darnerud, Serum levels of brominated flame retardants (BFRs: PBDE, HBCD) and influence of dietary factors in a populationbased study on Swedish adults, Chemosphere. 167 (2017) 485-491. doi:10.1016/j.chemosphere.2016.10.008.

[74] K. Jakobsson, J. Fång, M. Athanasiadou, A. Rignell-Hydbom, Å. Bergman, Polybrominated diphenyl ethers in maternal serum, umbilical cord serum, colostrum and mature breast milk. Insights from a pilot study and the literature, Environ. Int. 47 (2012) 121-130. doi:10.1016/j.envint.2012.05.006.

[75] D.F.K. Rawn, J.J. Ryan, A.R. Sadler, W.-F. Sun, D. Weber, P. Laffey, D. Haines, K. Macey, J. Van Oostdam, Brominated flame retardant concentrations in sera from the Canadian Health Measures Survey (CHMS) from 2007 to 2009, Environ. Int. 63 (2014) 26-34. doi:10.1016/j.envint.2012.05.008.

[76] D.S. Drage, J.F. Mueller, P. Hobson, F.A. Harden, L.-M.L. Toms, Demographic and temporal trends of hexabromocyclododecanes (HBCDD) in an Australian population, Environ. Res. 152 (2017) 192198. doi:10.1016/j.envres.2016.10.015.

[77] L. Meijer, J. Weiss, M. van Velzen, A. Brouwer, Å. Bergman, P.J.J. Sauer, Serum Concentrations of Neutral and Phenolic Organohalogens in Pregnant Women and Some of Their Infants in The Netherlands, Environ. Sci. Technol. 42 (2008) 3428-3433. doi:10.1021/es702446p.

[78] M. Kiciński, M.K. Viaene, E. Den Hond, G. Schoeters, A. Covaci, A.C. Dirtu, V. Nelen, L. Bruckers, K. Croes, I. Sioen, W. Baeyens, N. Van Larebeke, T.S. Nawrot, Neurobehavioral function and lowlevel exposure to brominated flame retardants in adolescents: a cross-sectional study, Environ. Heal. 11 (2012) 86. doi:10.1186/1476-069X-11-86.

[79] P.O. Darnerud, S. Lignell, M. Aune, M. Isaksson, T. Cantillana, J. Redeby, A. Glynn, Time trends of polybrominated diphenylether (PBDE) congeners in serum of Swedish mothers and comparisons to breast milk data, Environ. Res. 138 (2015) 352-360. doi:10.1016/j.envres.2015.02.031.

[80] J. Weiss, E. Wallin, A. Axmon, B.A.G. Jönsson, H. Åkesson, K. Janák, L. Hagmar, Å. Bergman, 
Hydroxy-PCBs, PBDEs, and HBCDDs in Serum from an Elderly Population of Swedish Fishermen's Wives and Associations with Bone Density, Environ. Sci. Technol. 40 (2006) 6282-6289. doi:10.1021/es0610941.

[81] C. Thomsen, H.K. Knutsen, V.H. Liane, M. Frøshaug, H.E. Kvalem, M. Haugen, H.M. Meltzer, J. Alexander, G. Becher, Consumption of fish from a contaminated lake strongly affects the concentrations of polybrominated diphenyl ethers and hexabromocyclododecane in serum, Mol. Nutr. Food Res. 52 (2008) 228-237. doi:10.1002/mnfr.200700123.

[82] X. Shi, Y. Du, P.K.S. Lam, R.S.S. Wu, B. Zhou, Developmental toxicity and alteration of gene expression in zebrafish embryos exposed to PFOS, Toxicol. Appl. Pharmacol. 230 (2008) 23-32. doi:10.1016/j.taap.2008.01.043.

[83] X. Shi, C. Liu, G. Wu, B. Zhou, Waterborne exposure to PFOS causes disruption of the hypothalamus-pituitary-thyroid axis in zebrafish larvae, Chemosphere. 77 (2009) 1010-1018. doi:10.1016/j.chemosphere.2009.07.074.

[84] J. Du, S. Wang, H. You, Z. Liu, Effects of ZnO nanoparticles on perfluorooctane sulfonate induced thyroid-disrupting on zebrafish larvae, J. Environ. Sci. 47 (2016) 153-164. doi:10.1016/j.jes.2016.01.018.

[85] X.-M. Ren, Y.-F. Zhang, L.-H. Guo, Z.-F. Qin, Q.-Y. Lv, L.-Y. Zhang, Structure-activity relations in binding of perfluoroalkyl compounds to human thyroid hormone T3 receptor, Arch. Toxicol. 89 (2015) 233-242. doi:10.1007/s00204-014-1258-y.

[86] J. Wang, D.R. Hallinger, A.S. Murr, A.R. Buckalew, S.O. Simmons, S.C. Laws, T.E. Stoker, HighThroughput Screening and Quantitative Chemical Ranking for Sodium-Iodide Symporter Inhibitors in ToxCast Phase I Chemical Library, Environ. Sci. Technol. 52 (2018) 5417-5426. doi:10.1021/acs.est.7b06145.

[87] C.M. Butt, H.M. Stapleton, Inhibition of Thyroid Hormone Sulfotransferase Activity by Brominated Flame Retardants and Halogenated Phenolics, Chem. Res. Toxicol. 26 (2013) 1692-1702. doi:10.1021/tx400342k.

[88] Y. Wu, F.A. Beland, J.-L. Fang, Effect of triclosan, triclocarban, 2,2',4,4'-tetrabromodiphenyl ether, 
and bisphenol A on the iodide uptake, thyroid peroxidase activity, and expression of genes involved in thyroid hormone synthesis, Toxicol. Vitr. 32 (2016) 310-319. doi:10.1016/j.tiv.2016.01.014.

[89] R. Shimizu, M. Yamaguchi, N. Uramaru, H. Kuroki, S. Ohta, S. Kitamura, K. Sugihara, Structureactivity relationships of 44 halogenated compounds for iodotyrosine deiodinase-inhibitory activity, Toxicology. 314 (2013) 22-29. doi:10.1016/j.tox.2013.08.017.

[90] K.B. Paul, J.M. Hedge, D.M. Rotroff, M.W. Hornung, K.M. Crofton, S.O. Simmons, Development of a Thyroperoxidase Inhibition Assay for High-Throughput Screening, Chem. Res. Toxicol. 27 (2014) 387-399. doi:10.1021/tx400310w.

[91] Y. Kudo, K. Yamauchi, H. Fukazawa, Y. Terao, In Vitro and In Vivo Analysis of the Thyroid System-Disrupting Activities of Brominated Phenolic and Phenol Compounds in Xenopus laevis, Toxicol. Sci. 92 (2006) 87-95. doi:10.1093/toxsci/kfj204.

[92] L. Baumann, A. Ros, K. Rehberger, S.C.F. Neuhauss, H. Segner, Thyroid disruption in zebrafish (Danio rerio) larvae: Different molecular response patterns lead to impaired eye development and visual functions, Aquat. Toxicol. 172 (2016) 44-55. doi:10.1016/j.aquatox.2015.12.015.

[93] W.K. Chan, K.M. Chan, Disruption of the hypothalamic-pituitary-thyroid axis in zebrafish embryolarvae following waterborne exposure to BDE-47, TBBPA and BPA, Aquat. Toxicol. 108 (2012) 106-111. doi:10.1016/j.aquatox.2011.10.013.

[94] J. Yang, K.M. Chan, Evaluation of the toxic effects of brominated compounds (BDE-47, 99, 209, TBBPA) and bisphenol A (BPA) using a zebrafish liver cell line, ZFL, Aquat. Toxicol. 159 (2015) 138-147. doi:10.1016/j.aquatox.2014.12.011.

[95] S. Kitamura, N. Jinno, S. Ohta, H. Kuroki, N. Fujimoto, Thyroid hormonal activity of the flame retardants tetrabromobisphenol A and tetrachlorobisphenol A, Biochem. Biophys. Res. Commun. 293 (2002) 554-559. doi:10.1016/S0006-291X(02)00262-0.

[96] S. Kitamura, T. Suzuki, S. Sanoh, R. Kohta, N. Jinno, K. Sugihara, S. Yoshihara, N. Fujimoto, H. Watanabe, S. Ohta, Comparative Study of the Endocrine-Disrupting Activity of Bisphenol A and 19 Related Compounds, Toxicol. Sci. 84 (2005) 249-259. doi:10.1093/toxsci/kfi074.

[97] K. Okada, T. Hiroi, S. Imaoka, Y. Funae, Inhibitory effects of environmental chemicals on protein 
disulfide isomerase in vitro., Osaka City Med. J. 51 (2005) 51-63.

http://www.ncbi.nlm.nih.gov/pubmed/16617682.

[98] S. Otsuka, A. Ishihara, K. Yamauchi, Ioxynil and Tetrabromobisphenol A Suppress ThyroidHormone-Induced Activation of Transcriptional Elongation Mediated by Histone Modifications and RNA Polymerase II Phosphorylation, Toxicol. Sci. 138 (2014) 290-299. doi:10.1093/toxsci/kfu012.

[99] J.B. Fini, A. Riu, L. Debrauwer, A. Hillenweck, S. Le mével, S. Chevolleau, A. Boulahtouf, K. Palmier, P. Balaguer, J.P. Cravedi, B.A. Demeneix, D. Zalko, Parallel biotransformation of tetrabromobisphenol A in Xenopus laevis and mammals: Xenopus as a model for endocrine perturbation studies, Toxicol. Sci. 125 (2012) 359-367. doi:10.1093/toxsci/kfr312.

[100] M. Terasaki, K. Kosaka, S. Kunikane, M. Makino, F. Shiraishi, Assessment of thyroid hormone activity of halogenated bisphenol A using a yeast two-hybrid assay, Chemosphere. 84 (2011) 15271530. doi:10.1016/j.chemosphere.2011.04.045.

[101] M.L. Jugan, M. Lévy-Bimbot, M. Pomérance, S. Tamisier-Karolak, J.P. Blondeau, Y. Lévi, A new bioluminescent cellular assay to measure the transcriptional effects of chemicals that modulate the alpha-1 thyroid hormone receptor, Toxicol. Vitr. 21 (2007) 1197-1205. doi:10.1016/j.tiv.2007.03.020.

[102] H. Sun, O.-X. Shen, X.-R. Wang, L. Zhou, S. Zhen, X. Chen, Anti-thyroid hormone activity of bisphenol A, tetrabromobisphenol A and tetrachlorobisphenol A in an improved reporter gene assay, Toxicol. Vitr. 23 (2009) 950-954. doi:10.1016/j.tiv.2009.05.004.

[103] M. Lévy-Bimbot, G. Major, D. Courilleau, J.-P. Blondeau, Y. Lévi, Tetrabromobisphenol-A disrupts thyroid hormone receptor alpha function in vitro: Use of fluorescence polarization to assay corepressor and coactivator peptide binding, Chemosphere. 87 (2012) 782-788. doi:10.1016/j.chemosphere.2011.12.080.

[104] M. Ghisari, E.C. Bonefeld-Jorgensen, Impact of environmental chemicals on the thyroid hormone function in pituitary rat GH3 cells, Mol. Cell. Endocrinol. 244 (2005) 31-41. doi:10.1016/j.mce.2005.01.013.

[105] D.A. Stavreva, L. Varticovski, L. Levkova, A.A. George, L. Davis, G. Pegoraro, V. Blazer, L. 
Iwanowicz, G.L. Hager, Novel cell-based assay for detection of thyroid receptor beta-interacting environmental contaminants, Toxicology. 368-369 (2016) 69-79. doi:10.1016/j.tox.2016.08.012.

[106] S. Strack, T. Detzel, M. Wahl, B. Kuch, H.F. Krug, Cytotoxicity of TBBPA and effects on proliferation, cell cycle and MAPK pathways in mammalian cells, Chemosphere. 67 (2007) S405S411. doi:10.1016/j.chemosphere.2006.05.136.

[107] E.K. Pacyniak, X. Cheng, M.L. Cunningham, K. Crofton, C.D. Klaassen, G.L. Guo, The Flame Retardants, Polybrominated Diphenyl Ethers, Are Pregnane X Receptor Activators, Toxicol. Sci. 97 (2007) 94-102. doi:10.1093/toxsci/kfm025.

[108] M. Schriks, E. Zvinavashe, J. David Furlow, A.J. Murk, Disruption of thyroid hormone-mediated Xenopus laevis tadpole tail tip regression by hexabromocyclododecane (HBCD) and 2,2',3,3',4,4',5,5',6-nona brominated diphenyl ether (BDE206), Chemosphere. 65 (2006) 1904-1908. doi:10.1016/j.chemosphere.2006.07.077.

[109] T. Yamada-Okabe, H. Sakai, Y. Kashima, H. Yamada-Okabe, Modulation at a cellular level of the thyroid hormone receptor-mediated gene expression by 1,2,5,6,9,10-hexabromocyclododecane (HBCD), 4,4'-diiodobiphenyl (DIB), and nitrofen (NIP), Toxicol. Lett. 155 (2005) 127-133. doi:10.1016/j.toxlet.2004.09.005.

[110] EFSA, Perfluorooctane sulfonate (PFOS), perfluorooctanoic acid (PFOA) and their salts - Scientific opinion of the Panel on Contaminants in the Food chain, EFSA J. 653 (2008) 1-131. doi:10.2903/j.efsa.2008.653.

[111] A.M. Seacat, P.J. Thomford, K.J. Hansen, L.A. Clemen, S.R. Eldridge, C.R. Elcombe, J.L. Butenhoff, Sub-chronic dietary toxicity of potassium perfluorooctanesulfonate in rats, Toxicology. 183 (2003) 117-131. doi:10.1016/S0300-483X(02)00511-5.

[112] SCCP, OPINION ON TRICLOSAN, Sci. Comm. Consum. Prod. SCCP. (2009). doi:10.2772/96027.

[113] L.M. Zorrilla, E.K. Gibson, S.C. Jeffay, K.M. Crofton, W.R. Setzer, R.L. Cooper, T.E. Stoker, The Effects of Triclosan on Puberty and Thyroid Hormones in Male Wistar Rats, Toxicol. Sci. 107 (2009) 56-64. doi:10.1093/toxsci/kfn225.

[114] EFSA, European Food Safety Authority (EFSA) panel on contaminants in the food chain 
(CONTAM): Scientific opinion on tetrabromobisphenol A (TBBPA) and its derivatives in food, 2011. doi:10.2903/j.efsa.2011.2477.

[115] L.T.M. Van der Ven, T. Van de Kuil, A. Verhoef, C.M. Verwer, H. Lilienthal, P.E.G. Leonards, U.M.D. Schauer, R.F. Cantón, S. Litens, F.H. De Jong, T.J. Visser, W. Dekant, N. Stern, H. Håkansson, W. Slob, M. Van den Berg, J.G. Vos, A.H. Piersma, Endocrine effects of tetrabromobisphenol-A (TBBPA) in Wistar rats as tested in a one-generation reproduction study and a subacute toxicity study, Toxicology. 245 (2008) 76-89. doi:10.1016/j.tox.2007.12.009.

[116] Y. Cai, W. Zhang, J. Hu, G. Sheng, D. Chen, J. Fu, Characterization of maternal transfer of decabromodiphenyl ether (BDE-209) administered to pregnant Sprague-Dawley rats, Reprod. Toxicol. 31 (2011) 106-110. doi:10.1016/j.reprotox.2010.08.005.

[117] EFSA, Scientific Opinion on Polybrominated Diphenyl Ethers ( PBDEs ) in Food, 2011. doi:10.2903/j.efsa.2011.2156.

[118] D.C. Rice, E.A. Reeve, A. Herlihy, R. Thomas Zoeller, W. Douglas Thompson, V.P. Markowski, Developmental delays and locomotor activity in the C57BL6/J mouse following neonatal exposure to the fully-brominated PBDE, decabromodiphenyl ether, Neurotoxicol. Teratol. 29 (2007) 511-520. doi:10.1016/j.ntt.2007.03.061.

[119] L.T.M. van der Ven, A. Verhoef, T. van de Kuil, W. Slob, P.E.G. Leonards, T.J. Visser, T. Hamers, M. Herlin, H. Håkansson, H. Olausson, A.H. Piersma, J.G. Vos, A 28-Day Oral Dose Toxicity Study Enhanced to Detect Endocrine Effects of Hexabromocyclododecane in Wistar Rats, Toxicol. Sci. 94 (2006) 281-292. doi:10.1093/toxsci/kfl113.

[120] D.T. Szabo, J.J. Diliberto, H. Hakk, J.K. Huwe, L.S. Birnbaum, Toxicokinetics of the Flame Retardant Hexabromocyclododecane Alpha: Effect of Dose, Timing, Route, Repeated Exposure, and Metabolism, Toxicol. Sci. 121 (2011) 234-244. doi:10.1093/toxsci/kfr059. 